\title{
Calculating gambling odds and lung ages
} for smokers

\author{
J.E. Hansen, X-G. Sun and K. Wasserman
}

\begin{abstract}
Interpreting spirometry as normal or abnormal using $95 \%$ confidence limits can obscure milder airflow decreases. Other analyses might better persuade cigarette smokers to quit.
\end{abstract}

High-quality spirometric data of ambulatory never- and current-smokers of African-, Europeanand Latin-American ethnicity from the Third National Health and Nutrition Evaluation Survey ( $n>9000)$ were analysed. We desired to calculate, for each decade of life, the odds that specific ratios of forced expiratory volume in $1 \mathrm{~s}$ to $6 \mathrm{~s}$ (\%FEV $1 / F E V 6)$ and to forced vital capacity (\%FEV $1 /$ FVC) values came from a current- or never-smoker. We also desired to develop new, simpler and better formulas to estimate changes in physiological lung age ( $\Delta$ lung age) for males and females.

For each decade of life, odds increase strikingly that smoking decreases $\% F V_{1} / F_{E V}$ and $\% F_{1} / F V C$. At least for these three ethnicities, $\Delta$ lung age can be easily calculated as the product of (predicted - actual) \%FEV $1 / F^{2} V_{6} \times 4$ or (predicted - actual) $\% F V_{1} / F V C \times 3$. Through the sixth decade of life, smokers' $\Delta$ lung age increase rapidly but little thereafter, presumably due to the inabilities of older smokers to participate in the survey or their deaths.

Using odds and $\Delta$ lung ages rather than traditional $95 \%$ confidence limits might better persuade smokers to quit.

KEYWORDS: Chronic obstructive pulmonary disease, lung age, ratio of forced expiratory volume in $1 \mathrm{~s}$ to $6 \mathrm{~s}$, ratio of forced expiratory volume in $1 \mathrm{~s}$ to forced vital capacity, spirometry

1 $\mathrm{t}$ is incumbent upon us to help persuade cigarette smokers to quit smoking and reduce suffering, pain, and premature deaths [1-5]. Increasing cigarette taxes, reducing locations where smoking is allowed, litigating, advertising the effects of tobacco smoking and increasing the stigma of smoking have all been helpful $[6,7]$. Health practitioners have assisted their patients by listening, counselling, referring to support groups and prescribing drugs to mollify withdrawal effects from nicotine [8-10]. However, spirometry has usually been of minimal benefit [11-13], perhaps because results are not presented optimally. Unfortunately, citing simplicity, the Global Initiative for Chronic Obstructive Lung Disease (GOLD) expert committee concluded that, even in younger individuals, all values of $\%$ forced expiratory volume in $1 \mathrm{~s}$ (FEV1)/forced vital capacity (FVC) $>70 \%$ are normal [5, 14], despite strong evidence and opposition to the contrary [15-17]. Alternatively, others rely on classical statistical analyses with 95\% confidence intervals and p-values of $<0.05$ to interpret their patients' spirometry [15].
We now question whether it is necessary for $\%$ FEV1/FVC values to be below these limits before concluding that airflow is reduced. We suggest two options for consideration: gambling odds and estimation of lung age. First, we can be like card players and gamblers by making decisions based on odds or probabilities without using a cut-off of $\mathrm{p}<0.05$; and secondly, we can simplify the estimation of spirometric lung age [18], as initially proposed by MORRIS and TEMPLE [19] and recently used with some benefit [20].

Therefore, using analyses of FEV1/ forced expiratory volume in $6 \mathrm{~s}$ (FEV6) and FEV1/FVC data from the Third National Health and Nutrition Evaluation Survey (NHANES-3) [21, 22], we relate airflow to gambling odds and lung age.

\section{METHODS} 9,353 self-identified European-American (white), African-American (black), and Mexican-American (Latin) adults with satisfactory spirometry [21, 22] between the ages of 20 and 80 yrs (see supplementary material).
We selected, from the NHANES-3 database [23],
AFFILIATIONS

Los Angeles Biomedical Research Institute and Division of Respiratory and Critical Care Physiology and Medicine; Dept of Medicine at Harbor-UCLA Medical Center, University of California David Geffen School of Medicine, Torrance, CA, USA.

CORRESPONDENCE

J.E. Hansen

Box 405

Dept of Medicine Harbor-UCLA

Medical Center

Torrance

CA 90502

USA

E-mail: jhansen@labiomed.org

Received:

July 102010

Accepted after revision:

Aug 312009

First published online:

Sept 242009 

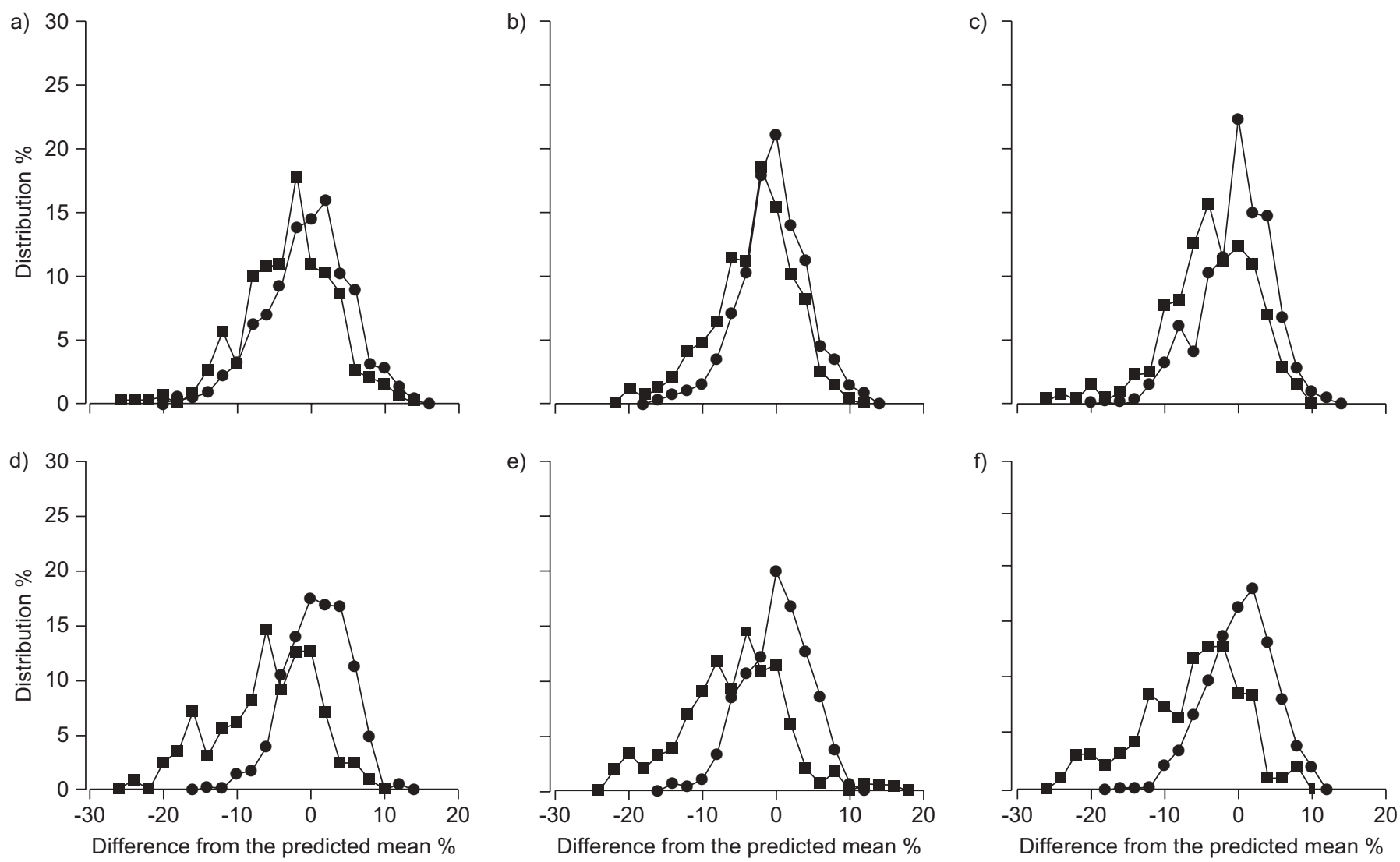

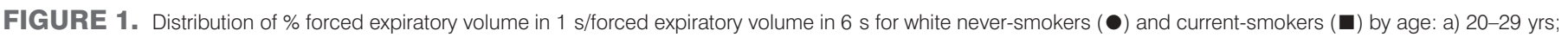
b) 30-39 yrs; c) 40-49 yrs; d) 50-59 yrs; e) 60-69 yrs; f) 70-79 yrs. Each never-smoker curve is normally distributed. The left-shifted curves of current-smokers, especially as ages increase, indicate increasing odds for current-smoking status.

We have previously calculated from NHANES-3 data that, for normal never-smoking adults, \%FEV1/FVC $=98.8-0.25 \times$ age (in yrs) $-1.79 \times$ FVC (in L), independent of ethnicity and sex [24, 25]. We now similarly have developed the formula: \%FEV1/ $\mathrm{FEV}_{6}=96.9-0.189 \times$ age $($ in $\mathrm{yrs})-1.524 \times \mathrm{FEV}_{6}$ (in L) $($ standard error of estimate $4.7 \%$ ).

We measured the percentage differences between predicted and actual \%FEV1/FEV6 in each subject, which allowed us to graph, for each decade, the distribution of the \%FEV1/FEV 6 of 5,835 never-smokers about their predicted values and, separately, the same for 3,518 current-smokers. We could then calculate within each decade, the gambling odds that, at any given deviation from mean predicted value, the actual \%FEV1/ FEV6 of an individual might be that of a current-smoker or never-smoker.

We developed a new formula relating how the percentage differences between actual and predicted spirometric values were related to changes in physiological lung age ( $\Delta$ lung age) (see supplementary material). For each adult, we calculated that $\Delta$ lung age $=4 \times\left((\%\right.$ predicted- $\%$ actual $\left.) \% F E V 1 / \mathrm{FEV}_{6}\right)$ and $=3 \times((\%$ predicted- $\%$ actual $) \% F E V 1 / F V C)$. Then, using the formulas of MORRIS and TEMPLE [19], we calculated the lung ages for each white adult. This allowed both sets of formula to be compared for never- and current-smokers for each decade by two-tailed unpaired t-tests with a p-value $<0.05$ being considered significant [26].

\section{RESULTS}

By GOLD categories, none of the current-smokers was verysevere GOLD (FEV1 <30\%), $0.8 \%$ were severe category (FEV1 $=30-50 \%), 6.5 \%$ were moderate GOLD (FEV1 $=50-80 \%)$ and $10.4 \%$ were mild GOLD (FEV1 $>80 \%$ ) (see fig. $1 \mathrm{e}$ and supplementary material) [5].

\section{Gambling odds}

Figure 1 displays the actual distribution, by $2 \%$ bins, for the third to eighth decade of life for \% FEV1/FEV6 for white adults. The patterns were quite similar for other ethnicities using either the \% FEV1/FVC or \% FEV1/FEV6 formulas. Table 1 lists the resultant prevalence (gambling) odds that, for a given difference between actual and predicted \%FEV1/FVC, a value is from a current- or never-smoker. As the actual $\%$ FEV1/FVC decrease a few percentages from mean predicted, the odds increase above 1.0, tending to identify currentsmokers rather than never-smokers. Conversely, odds of $<1.0$ tend to identify never-smokers. As seen in figure $2 \mathrm{e}$ in the supplementary material, discrimination of reduced airflow attributable to smoking is evident at age 25 yrs but strikingly greater at age 55 yrs.

\section{Lung age formula comparisons}

Figure 2a shows the Morris and Temple mean lung ages for white never- and current smokers by decade of age using sex, age and FEV1 or sex, age and FVC. Note that the never-smokers' 


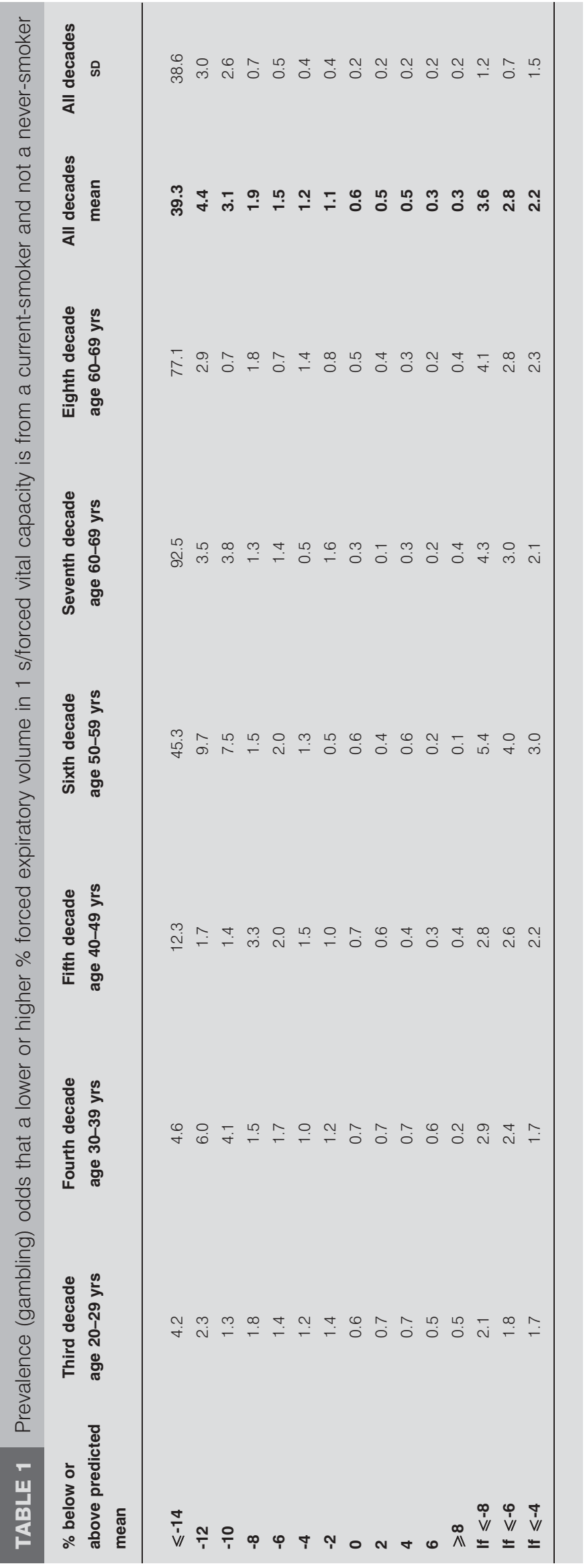

mean lung ages are usually considerably less than their actual ages while the current-smokers' mean lung ages exceed their actual ages. In the same population, figure $2 \mathrm{~b}$ shows that for either the Harbor \% FEV1/FVC or \% FEV1/FEV6 formulas, never-smokers' mean lung ages approximate their actual age, while the current-smokers lung age differences increase decade by decade for both sexes up to the sixth decade of life. Thereafter, the lung age differences levelled off at $\sim 25$ yrs. For all decades, current-smokers differed from never-smokers by $7-$ 28 yrs $(p<0.0001)$ with either Harbor formula. Figures $2 c$ and $2 d$ show the lung age findings in black and Latin adults using the Harbor formulas, sometimes with lesser but still statistically significant difference between never- and current-smokers.

\section{DISCUSSION}

Subtle reductions in airflow should be discernible well before a clinical diagnosis of COPD can be made [27, 28]. The presentation of gambling odds is used to challenge the deeply held belief that $95 \%$ confidence limits should be the primary criteria to decide whether a patient has reduced airflow. 95\% confidence limits are appropriate to analyse treatment differences but are not ideal in distinguishing the effects of whether or not exposure to a substance is harmful. Gambling odds remind us that probabilities other than $5 \%$ or 20 to 1 can be useful. For example, a family may decide to live in site A, not because it is 20 -times better than site B, but because site $\mathrm{A}$ is $10 \%$ or $20 \%$ or $30 \%$ safer (or cleaner, or more attractive) than site B. These odds are $1.1,1.2$, or 1.3 for choosing site A. Although airflow is influenced by health, genetics, nutrition, motivation and environmental factors, a Bayesian approach tells us that the influence of cigarette smoking on airflow need not be ignored with relative odds of $1.1,1.2$, and 1.3 , to say nothing when relative odds of 2 or 5 are found.

MorRIS and TEMPLE [19] deserve credit for introducing the concept of lung age to assess airflow obstruction. PARKES et al. [20] found their lung ages useful, but they are not routinely calculated. Using the new formulas presented here, anyone can easily manually calculate and inform patients of their $\Delta$ lung ages from any spirometric report. For example if a patient's actual $\%$ FEV $1 / \mathrm{FEV}_{6}$ is $3 \%$ below predicted, or $\% \mathrm{FEV} 1 / \mathrm{FVC}$ is $4 \%$ below predicted, the $\Delta$ lung age is +12 yrs. This should elicit a response and open discussion regarding the dangers of continuing cigarette smoking. Referral to support groups, educational and counselling sessions, and the use of newer pharmaceuticals all offer avenues for success $[8,9,20,29,30]$.

Cigarette smoking is the leading cause of preventable morbidity and mortality $[1,2,5]$. Airway and vascular obstruction, both worsened by smoking, are usually parallel processes [4, 13, 3135], but airway obstruction is cheaper and quicker to assess. There have been significant declines in death rates and morbidity from cardiovascular diseases [36], but a parallel decline in airway diseases and lung cancer attributable to cigarette smoking is not yet obvious, especially in females $[1,2,5]$. Simple and compelling advocacy is even more necessary where cigarette smoking is more openly tolerated and promoted.

\section{Limitations}

We believe our analysis of the cross-sectional NHANES-3 data underestimates the significance of the effect of cigarette smoking on airflow, morbidity, and mortality. One factor is 

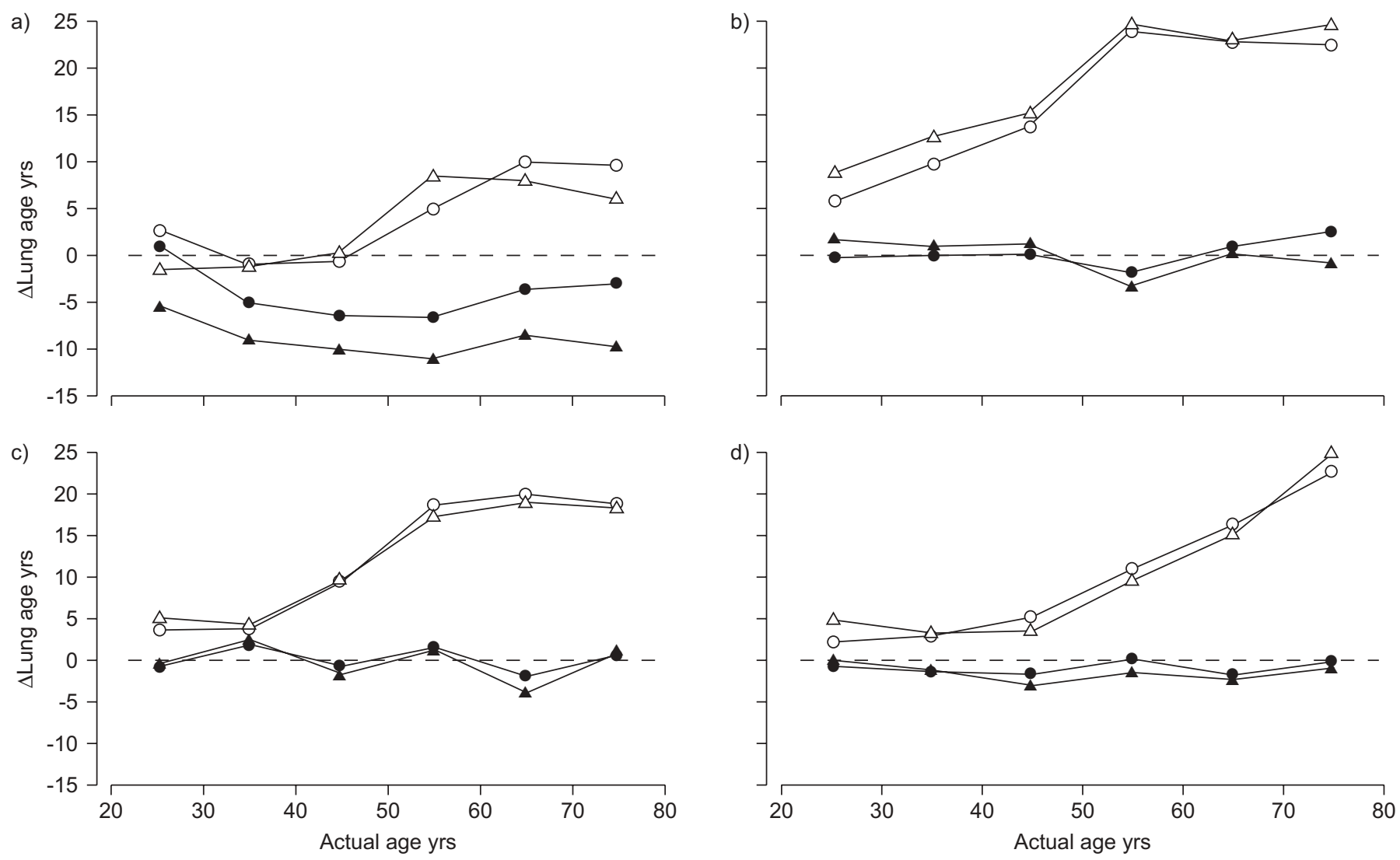

FIGURE 2. Lung age changes by decade for never-smokers $(\bullet, \mathbf{\Delta})$ and current-smokers $(\bigcirc, \triangle)$ measured. a) White adults with the Morris formula. $\mathbf{\Delta}$ and $\triangle$ : forced expiratory volume in $1 \mathrm{~s}\left(F_{E V}\right)$; $\bullet$ and $\bigcirc$ : forced vital capacity (FVC). Harbor formula for b) white adults, c) black adults and d) Latin adults. $\mathbf{\Delta}$ and $\triangle$ : FEV $1 / F E V 6 ; \bullet$ and $\bigcirc$ : FEV1/FVC. a) For the third decade (ages 20-29 yrs); white current- and never-smokers differed by 4 yrs $(p=0.003)$ using FEV 1 and 2 yrs ( $p=0.43$ ) using FVC. For older decades, FEV1 values differed by $8-20$ yrs $(p<0.0001)$ while FVC values varied by $5-14$ yrs $(p=0.0008-0.014)$. $c)$ Black current-smokers differed from never-smokers by 5 $24 \mathrm{yrs}(\mathrm{p}<0.001)$ for all but the fourth decade (ages 30-39 yrs) when the differences were only 2-3 yrs $(p=\sim 0.08)$. d) Latin current-smokers differed from never-smokers by $3-5$ yrs $(p=\sim 0.01)$ for the third and fourth decades, and 7-26 yrs $(p<0.001)$ for all other decades.

the lack of continuing rise in airway obstruction after the sixth decade in the White and Black subjects. First, we suggest that increased mortality (due to malignancies, COPD, or cardiovascular diseases) plus the severe morbidity and lack of mobility in older smokers was likely responsible. Secondly, the lower number of current smokers than never-smokers in the seventh and eighth decades would support that possibility. Thirdly, considering the high morbidity associated with COPD, malignancies, and cardiovascular diseases, the finding that no one in the never-smoking population met the GOLD criteria [5] of very severe COPD (\%FEV1/FVC $<70 \%$ and FEV1 $<30 \%$ of predicted), and $<1 \%$ had severe COPD (\%FEV1/FVC $<70 \%$ and $\mathrm{FEV} 1 \geqslant 30 \%$ and $<50 \%$ ) supports this underrepresentation of disease. Furthermore, exposure of many never-smokers to second-hand smoke or to other important pollutants may have reduced differences between the neversmoking and current-smoking groups [37].

Because there is marked variability in the spirometric ratios of normal individuals, unexplained by height, age, sex or ethnicity, not all current-smokers have lower than mean predicted $\% \mathrm{FEV} 1 / \mathrm{FEV} 6$ or $\% \mathrm{FEV} 1 / \mathrm{FVC}$, and not all neversmokers have higher than mean predicted $\% \mathrm{FEV} 1 / \mathrm{FEV} 6$ or $\%$ FEV1/FVC (see supplementary material).

\section{Conclusion}

Simple formulas for assessing normality of \%FEV1/FEV 6 and $\%$ FEV1/FVC values are presented. They allow any health professional receiving a spirometry report to calculate some of the detrimental effects of cigarette smoking on airflow and lung age and thus better inform, challenge, and support their patients to quit smoking.

\section{STATEMENT OF INTEREST}

None declared.

\section{ACKNOWLEDGEMENTS}

The authors would like to thank the USA government agencies, investigators, technicians and subjects of NHANES-3 who together acquired the data and made it available to us for further analyses.

\section{REFERENCES}

1 US Cancer Statistics Working Group. United States Cancer Statistics: 2004 Incidence and Mortality. Atlanta (GA): Department of Health and Human Services, Centers for Disease Control and Prevention, and National Cancer Institute; 2007.

2 Centers for Disease Control and Prevention. Annual smokingattributable mortality, years of potential life lost, and productivity 
losses - United States, 1997-2001. Morb Mort Wkly Rep 2005; 54: 625-628.

3 deVerdier MG. The big three concept: a way to tackle the health care crisis? Proc Am Thorac Soc 2008; 5: 800-805.

4 Rennard SI. Lessons from multidisciplinary cross-fertilization: chronic obstructive lung disease, lung cancer, and heart disease. Proc Am Thorac Soc 2008; 5: 865-868.

5 Global Stategy for the Diagnosis, Management and Prevention of COPD, Global Initiative for Chronic Obstructive Lung Disease (GOLD) 2008. Available from: www.goldcopd.org

6 Alamar B, Glantz S. Effect of increased social unacceptability of cigarette smoking on reduction in cigarette consumption. Am J Public Health 2006; 96: 359-363.

7 Vernick JS, Rutkow L, Teret SP. Public health benefits of recent litigation against the tobacco industry. JAMA 2007; 298: 86-89.

8 Carrozzi L, Pistelli F, Viegi G. Pharmacotherapy for smoking cessation. Ther Adv Respir Dis 2008; 2: 301-317.

9 Fagerstrom KG, Jiminez-Ruiz CA. Pharmacological treatments for tobacco dependence. Eur Respir Rev 2008; 17: 192-198.

10 Cornuz J, Willi C. Non-pharmacological smoking cessation interventions in clinical practice. Eur Respir Rev 2008; 17: 187-191.

11 Wilt TJ, Niewoehner D, Kim C, et al. Use of spirometry for case finding, diagnosis, and management of chronic obstructive lung disease (COPD). Evid Rep Technol Assess (Summ) 2005; 121: 1-7.

12 Boushey H, Enright P, Samet J. Spirometry for chronic obstructive pulmonary disease case finding in primary care? Am J Respir Crit Care Med 2005; 172: 1481-1482.

13 Kotz D, Wessling G, Hulbers MJH, et al. Efficacy of confronting snokers with airflow limitation for smoking cessation. Eur Respir J 2009; 33: 754-762.

14 Mannino DM. Should we be using statistics to define disease? Thorax 2008; 63: 1031-1032.

15 Pelligrino R, Viegi G, Brusasco V, et al. ATS/ERS task force: Standardization of lung function testing: interpretative strategies for lung function tests. Eur Respir J 2005; 26: 948-968.

16 Hansen JE, Sun XG, Wasserman K. Spirometric criteria for airway obstruction: use percentage of FEV1/FVC ratio below the fifth percentile, not $<70 \%$. Chest 2007; 131: 349-355.

17 Swanney MP, Ruppel G, Enright PL, et al. Using the lower limit of normal for the FEV1/FVC ratio reduces the misclassification of airway obstruction. Thorax 2008; 63: 1046-1051.

18 Kazuhiro I, Barnes PJ. COPD as a disease of accelerated lung aging. Chest 2009; 135: 173-180.

19 Morris JF, Temple W. Spirometric "lung age" estimation for motivating smoking cessation. Prev Med 1985; 14: 655-662.

20 Parkes G, Greenhalgh T, Griffin M, et al. Effect on smoking quit rate of telling patients their lung age: the Step2quit randomised controlled trial. BMJ 2008; 336: 598-600.
21 US Department of Health and Human Services (DHHS) National Center for Health Statistics. Third national health and nutrition examination survey, 1998-1994: NHANES III raw spirometry data file. Hyattsville, MD: Centers for Disease Control and Prevention, 2001. www.cdc.gov/nchs/nhanes/nh3data.htm Date last updated January 28, 2010.

22 Hankinson JL, Odencrantz JR, Fedan KB. Spirometric reference values from a sample of the general US population. Am J Respir Crit Care Med 1999; 159: 179-187.

23 American Thoracic Society. Standardization of spirometry. 1994 update. Am J Respir Crit Care Med 1995; 152: 1107-1136.

24 Hansen JE, Sun X-G, Wasserman K. Discriminating measures and normal values for expiratory obstruction. Chest 2006; 129: 369-377.

25 Hansen JE, Sun X-G, Wasserman K. Ethnic- and sex-free formula for detection of airway obstruction. Am J Respir Crit Care Med 2006; 174: 493-498.

26 Dixon WJ, Massey FJ Jr. Introduction to Statistical Analysis. 3rd Edn. New York, McGraw-Hill, 1969.

27 Doherty DE. A review of the role of FEV1 in the COPD paradigm. COPD 2008; 5: 310-318.

28 Fletcher C, Peto R. The natural history of chronic airflow obstruction. BMJ 1977; 1: 1645-1648.

29 Tashkin DP, Murray RP. Smoking cessation in chronic obstructive pulmonary disease. Respir Med 2009; 103: 963-974.

30 Lee TA, Bartle B, Weiss KB. Spirometry use in clinical practice following diagnosis of COPD. Chest 2006; 129: 1509-1515.

31 Wilson D, Adams R, Appleton S, et al. Difficulties identifying and targeting COPD and population-attributable risk of smoking for COPD. Chest 2005; 128: 2035-2042.

32 Brook RD, Franklin B, Cascio W, et al. Air pollution and cardiovascular disease: a statement for healthcare professionals from the expert panel on population and prevention science of the American Heart Association. Circulation 2004; 109: 2655-2671.

33 Miller KA, Siscovick DS, Sheppard L, et al. Long-term exposure to air pollution and incidence of cardiovascular events in women. N Engl J Med 2007; 356: 447-458.

34 Frostad A, Soyseth V, Haldorsen T, et al. Respiratory symptoms and long term cardiovascular mortality. Respir Med 2007; 101: 2289-2296.

35 Iwamoto H, Yokoyama A, Kitahara Y, et al. Airflow limitation in smokers is associated with subclinical atheroscelerosis. Am J Respir Crit Care Med 2009; 179: 35-40.

36 Cardiovascular disease statistics. www.americanheart.org/ presenter.jhtml?identifier $=4478$ Date last accessed: January 29, 2010.

37 Schane RE, Glantz SA. Education on the dangers of passive smoking: a cessation strategy. Circulation 2008; 118: 1521-1523. 